\title{
ASPECTOS HISTÓRICOS DO ENSINO DE LÍNGUA INGLESA NO BRASIL: UMA ANÁLISE DISCURSIVA DO SUJEITO NA PUBLICIDADE AUDIOVISUAL DE CURSOS DE IDIOMAS
}

\section{Welisson MARQUES*}

Se o discurso é um lugar de memória, é porque ele traz o vestígio - inscrito nas suas formas - das flutuações e das contingências de uma estratégia; a impressão sedimentada de uma história, de suas continuidades e de suas rupturas. Fazer a análise do discurso é aprender a deslinearizar o texto para restituir sob a superficie lisa das palavras a profundeza complexa dos indices de um passado.

Jean-Jacques Courtine (2006, p. 91-92)

A análise do discurso assim entendida não desvenda a universalidade de um sentido; ela mostra à luz do dia o jogo de rarefação imposta, com um poder fundamental de afirmação. Rarefação e afirmação, rarefação, enfim, da afirmação e não generosidade contínua do sentido, e não monarquia do significante.

Michel Foucault (1996 [1971], p. 66)

- RESUMO: Inscrito sob o viés teórico da Análise do Discurso, este artigo apresenta como objetivo geral analisar a constituição do sujeito enunciador no discurso publicitário de cursos de idiomas no Brasil. Nesse sentido, buscaremos analisar como o sujeito significa aprendiz e aprendizagem de língua inglesa nesses espaços enunciativos. Para isso, traremos à discussão, a priori, alguns aspectos históricos que permeiam o ensino de língua inglesa em nosso país. $\mathrm{Na}$ sequência, trataremos da base metodológica que constitui a pesquisa ora arrolada nesta reflexão, para enfim, efetuarmos nossas análises. Destacamos, no batimento descriçãointerpretação, que os enunciados, de modo regular, evidenciam a importância suprema da habilidade oral. Isso se apresenta na constante mobilização linguística do lexema falar em suas diversas flexões. Outrossim, verifica-se a supremacia do estrangeiro em relação ao brasileiro e, por fim, a exigência que recai sobre o aprendiz brasileiro de língua inglesa em possuir uma pronúncia "perfeita".

- PALAVRAS-CHAVE: Aprendiz. Aprendizagem. Discurso. Língua inglesa. Publicidade.

\footnotetext{
* Instituto Federal de Educação, Ciência e Tecnologia do Triângulo Mineiro (IFTM), Uberaba - MG - Brasil. welissonmarques@iftm.edu.br. ORCID: 0000-0001-6766-4651.
} 


\section{Considerações Introdutórias}

Este artigo alvitra analisar como se constitui o sujeito enunciador em discursos de cursos de idiomas no Brasil, mais especificamente na publicidade audiovisual. Nesse sentido, buscaremos evidenciar como o sujeito significa aprendiz e aprendizagem de língua inglesa nesses espaços enunciativos.

No primeiro tópico, intitulado Aspectos históricos do ensino de língua inglesa no Brasil, realizaremos uma retomada do ensino de língua inglesa no país desde sua instituição oficial no início do século XIX até a atualidade. Todo discurso pressupõe um conjunto de verdades que lhe dá sustentação e pelo fato de tratarmos da linguagem em curso - definição do próprio discurso -, para uma melhor compreensão do discurso de cursos de idiomas na hodiernidade, apresentaremos um panorama do ensino de língua inglesa no país. Isso se dá em virtude da natureza do objeto, isto é, do discurso publicitário se imbricar ao discurso institucional de cursos de idiomas.

Na sequência, em Especificidades do sujeito enunciador: Breve caracterização do instituto, exporemos, de modo geral, uma descrição do instituto com vias a melhor conhecer aquele(s) que endossa(m) a peça publicitária. Isso se dá em virtude de em Análise do Discurso se fazer necessário conhecer as condições de produção do discurso analisado.

O tópico seguinte, Análise do Discurso e enunciado, servirá para pontuar qual é a base teórico-metodológica adotada, em especial, definindo o conceito de enunciado. $\mathrm{O}$ enunciado é um acontecimento que nem a língua nem o sentido podem esgotar totalmente e sua noção é pensada em uma perspectiva em que ao analista cabe observar suas relações com outros enunciados em dispersão, e mesmo em ordens e domínios diferentes e divergentes. Assim, o enunciado é ao mesmo tempo singular (em seu momento de irrupção) quanto pertencente a uma rede, a um "todo" histórico do qual não se pode desvencilhar (FOUCAULT, 1995 [1969]).

Feitas estas considerações, após a exposição deste conceito e fechamento deste tópico, logo avançaremos para a análise do corpus a partir da proposta teórica adotada.

\section{Aspectos históricos do ensino de língua inglesa no Brasil}

Em razão dos inúmeros deslocamentos de ordem social na história em cujo movimento o sujeito está inserido, novas nuances certamente irrompem nos discursos sobre aprendiz brasileiro e aprendizagem de língua inglesa nessa segunda década do século XXI. Por esta razão, buscar descrever e interpretar o porquê dado sujeito assume determinadas posições em um contexto social específico implica um voltar-se para as condições histórico-culturais que sobre ele intervém, bem como as conjunturas políticas, econômicas e tecnológicas que interferem em sua constituição.

$\mathrm{O}$ ensino de língua inglesa se oficializou no país no início do século XIX em uma época em que juntamente com o francês possuía força e status político, cultural 
e comercial tanto no Brasil, quanto em toda a Europa, especialmente se se considerar que se trata de um período pós-independência americana (1776) e revolução francesa (1789). Foi por meio da lei de 22 de junho de 1809 que se instituíram o ensino das línguas inglesa e francesa na Corte do Brasil. Cita o dispositivo legal de então:

E, sendo outrossim, tão geral e notoriamente conhecida a necessidade de utilizar das línguas francesa e inglesa, como aquelas que entre as vivas têm mais distinto lugar, e é de muita utilidade ao estado, para aumento e prosperidade da instrução pública, que se crie na Corte uma cadeira de língua francesa e outra de inglesa. (MOACYR, 1936, p. 61)

Nessa época, a língua inglesa não possuía tanta importância quanto a francesa (esta última era a lingua franca desse período), pois como se não a exigia nas academias, seu ensino só era tido como necessário nos estudos secundários em virtude do aumento de relações entre Portugal e Inglaterra.

Entre 1808 e 1821, período do reinado de D. João VI, a língua inglesa era colocada em terceiro lugar atrás do latim, considerada a língua da literatura e religião, e do francês, tida como língua universal e cultural. O inglês era uma opção profissional para os "mais avançados" estudantes. Em termos sociais, o acesso à educação de línguas era exclusivo à minoria latifundiária e aristocrática da Corte. Além disso, não foi pelo fato de se instituir a língua inglesa que seu ensino se expandiu nessa época. Como afirmamos, em virtude de seu conhecimento não ser exigido para acesso às academias, por muitos anos houve reduzida demanda de alunos.

A língua inglesa passou a fazer parte do currículo obrigatório de determinados colégios e liceus apenas em 1837, sendo instituídos seu programa e carga horária. Todavia, no primeiro levantamento regional do ensino brasileiro, datado de 1852, o Dr. Antônio Gonçalves Dias definiu como "desgraçado" o estado das instituições provinciais por ele visitadas, isso em um contexto onde o inglês já fazia parte da maioria dos liceus, seminários, escolas normais e primárias de então (OLIVEIRA, 1999).

$\mathrm{Na}$ segunda metade do século XIX, o ensino do inglês "se manteve voltado para finalidades exclusivamente práticas, exigindo do aluno apenas os conhecimentos gramaticais necessários à leitura, versão e tradução de textos escritos - habilidades que eram cobradas nos exames de preparatórios das academias" (OLIVEIRA, 1999, p. 166). Em comparação com outras disciplinas, a língua inglesa manteve o número reduzido de aulas e, além disso, de acordo com o decreto 2.857 de 1.898 , que dividia o ginásio em dois cursos distintos e concomitantes - um curso introdutório e mais realista com duração de 6 anos e outro mais humanista, de 7 anos, as línguas vivas estrangeiras, incluindo o inglês, eram optativas em praticamente todos os anos desses dois cursos que compunham o ginasial.

Portanto, o século XIX assistiu, de modo geral, à deficiência do ensino de língua inglesa nas províncias do Império, tanto nas instituições públicas, quanto particulares. Isso ocorreu pelo fato da disciplina receber um número de aulas relativamente reduzido, 
por ser estabelecida como matéria optativa - a partir de alguns decretos -, ou mesmo em virtude de carências de ordem técnica, descritas por Gonçalves Dias, e já assinaladas anteriormente.

É preciso pontuar, no cerne desse esboço histórico, que a despeito de alvitrarmos analisar institutos particulares de idiomas, ao tratar sobre o ensino de LE em uma perspectiva que contempla as relações do aprendiz brasileiro com a língua e com o estrangeiro, é insuficiente um olhar apenas sobre "uma história do ensino privado de língua inglesa no país". Em outros termos, conhece-se melhor o sujeito, lançando luz sobre dada memória que norteia os discursos desses ou sobre esses mesmos sujeitos, até porque a expansão do ensino de línguas por meio de institutos particulares não se deu antes de meados do século XX.

Assim, se por um lado o estudo de línguas vivas na virada do século XIX e início do século XX parecia estar aquém do esperado, um decreto datado de 1911 apresentava-se, ao nosso entender, e em virtude da realidade que se constatava, como ambicioso em suas propostas. Declara o texto (OLIVEIRA, 1999, p. 65): “Ao estudo das línguas vivas será dado feição prática; [...] no fim do curso deverão [os alunos] estar habilitados a falar e escrever duas línguas estrangeiras e familiarizados com a evolução literária delas". Como se sabe, teoria e prática nem sempre caminham em sintonia. Não é pelo fato de se efetuarem propostas por meio de dispositivos legais que, na prática, alcançavam-se resultados à sua altura (de tais propostas). Outrossim, deve-se levar em conta também o rápido crescimento populacional e concomitante necessidade de expansão de colégios que, certamente, não acompanharam a qualidade dos primeiros liceus da época, tidos como exemplares, como é o caso do Colégio Pedro II no Rio de Janeiro.

\begin{abstract}
A situação do ensino de inglês no país só iria se modificar com a reforma do ministro Francisco Campos - mais precisamente com a Portaria de 30 de junho de 1931, que especificou os objetivos, conteúdo e, pela primeira vez, a metodologia do ensino de cada disciplina do "curso fundamental". Com tal regulamento, começou a ser enfatizado o "sistema fonético estrangeiro" e a "leitura de textos fonética e ortograficamente escritos", o que fez com que o ensino das línguas vivas estrangeiras logo passasse a ter um método oficial: o "método direto intuitivo", segundo o qual a língua estrangeira deveria ser ensinada na própria língua estrangeira. (OLIVEIRA, 1999, p. 168).
\end{abstract}

Nesse trajeto do ensino de língua inglesa no Brasil não se pode olvidar da estreita relação da história, de fatores históricos, com o ensino, ou seja, os processos de subjetivação do sujeito se dão nas práticas discursivas, sendo que o sujeito sempre se constitui historicamente. Isso foi apontado por Foucault em diversas obras, em especial em sua incursão histórica sobre a produção de subjetividade exposta em Hermenêutica do Sujeito ([1981-1982] FOUCAULT, 2010). No que tange ao sujeito aprendiz brasileiro 
de língua inglesa, percebemos que a "colonização" foi e ainda é um relevante fator de regulação dos discursos dos sujeitos.

Nesse sentido, a "dependência" do Brasil é histórica. Na verdade, foi somente a partir da primeira guerra mundial, segundo Pinto (1986), que houve um deslocamento de "dependência" do Brasil em relação ao eixo Portugal-Europa para os Estados Unidos da América. Ao tratar dessa relação de subserviência, Paiva (1996, p. 24) destaca: "a partir de 1921, a dependência para com os norte-americanos aumentou com a crise do café, tendo o Brasil que recorrer a constantes empréstimos. A dependência econômica gerou uma dependência cultural". Assim, segundo a autora, a dominação se evidencia em diversas facetas sociais: econômica, cultural, social, política e linguística. No âmbito cultural Ianni (1976, p. 56) destaca: "as pessoas, grupos e classes sociais alcançados por essa indústria [cultural] são induzidos a pensar e a expressarem-se principalmente nos termos e segundo os objetivos dos que a controlam. Esse processo de massificação é importante para a perpetuação das estruturas socioeconômicas geradas pelo sistema capitalista".

No âmbito linguístico, ao tratar sobre a língua inglesa no Brasil, Paiva (1996, p. 26) também destaca a influência estrangeira sobre a maciça circulação de palavras em nosso país: "A importação de palavras estrangeiras atende muito mais a uma necessidade simbólica de identificação com uma sociedade de grande poder político e econômico do que a necessidade de nomear novos conceitos e objetos". À diferença de Paiva que trata exclusivamente da dominação linguística, apontamos também as imagens (símbolos, ícones), sons (músicas, trilhas sonoras de filmes), e mesmo hábitos de ordem cultural (alimentação, vestuário, moda...) adotados e praticados por sujeitos aprendizes brasileiros e que funcionam, ao nosso entender, como resultado de processos de subjetivação históricos, fruto de um imperialismo cultural e da dependência econômica de séculos.

Desse modo, não se trata apenas de uma cultura imperialista dominar outra, mas de como a cultura dita "dominada" absorve, ou melhor, se subjetiva face a esses discursos. Como já disse Moita Lopes (1996, p. 47, grifo nosso): "Transmitir cultura significa impor a ideologia da classe dominante, que vai, é óbvio, atender diretamente aos seus próprios interesses".

Se, por um lado, o sujeito do mundo globalizado na era pós-moderna não encara dificuldades em se filiar a novas identidades, pois como declara Bauman (2005, p. 91): "A liberdade de alterar qualquer aspecto e aparência da identidade individual é algo que a maioria das pessoas hoje considera prontamente acessível, ou pelo menos, vê como uma perspectiva realista para o futuro próximo", por outro, é interessante o fato de o aprendiz brasileiro de língua inglesa permanecer filiado a lugares que tendem a "diminuí-lo", mantê-lo em posição subalterna.

Certamente, conforme assinalamos, aspectos inerentes a essas verdades procedem de um legado histórico colonialista e que se reflete indubitavelmente nas práticas do aprendiz de LE: "As pessoas internalizam inconscientemente as crenças sobre linguagem durante a vida toda e assim as crenças sobre o que é linguagem, linguagem adequada e 
assim por diante, variam de indivíduo para indivíduo e são profundamente mantidas" (WOODS, 1996, p. 186, tradução nossa, grifo nosso).

Uma análise dos discursos dos institutos de idiomas permite-nos reconhecer quais verdades são construídas sobre esses sujeitos e como o sujeito enunciador busca evidenciar algumas ou sancionar outras ao corpo social e, também, como essas verdades/ crenças, ao serem assimiladas por outros sujeitos, tornam-se verdades e interferem no processo de identificação e aprendizagem da LE. Ressalta-se que não se efetua, neste artigo, uma análise direta do sujeito-aprendiz, mas de um sujeito que enuncia em uma perspectiva que contempla modos de ser e agir do aprendiz de LE.

Como citamos anteriormente, a situação no ensino de língua inglesa, segundo Oliveira (1999), só se modificaria no país a partir de 1931 com uma Portaria que especificaria os objetivos, conteúdo e metodologia no ensino fundamental. Concomitante a essas mudanças sociais, foi a partir deste ano também que começaram a surgir os institutos particulares, tal qual ora analisado, um dos mais tradicionais a trabalhar na modalidade presencial, e inaugurado em 1934 no Rio de Janeiro.

No entanto, a expansão de cursos particulares não se deu antes da segunda metade do século XX. Nesse contexto, as décadas de 1960, 1970 e 1980 assistiram ao surgimento, expansão e consolidação de inúmeros cursos de inglês. Em um recenseamento realizado dos cursos de idiomas mais expressivos, constatamos que o setor privado de ensino de idiomas exerce um papel fundamental na formação de aprendizes de língua inglesa em nosso país. As doze franquias por nós listadas agregam o impressionante número de 5.102 unidades.

Assim, essas franquias são responsáveis pela formação de aprendizes em um considerável número de municípios brasileiros e sua expansão não se deu ao acaso. Como verificamos na exposição histórica sobre aprendizagem de língua inglesa no Brasil, o ensino público, desde sua instituição, sempre enfrentou deficiências e problemas gravíssimos, gerindo o discurso, ainda muito atual, de que não é possível aprender uma língua estrangeira na escola pública. A expansão no setor privado certamente foi impulsionada por esses fatores ${ }^{1}$. De tal sorte, o instituto particular "preenche" uma lacuna social, e torna-se responsável e legitimado pelo ensino eficaz da LE. Seria, portanto, o lugar exclusivo onde o aprendiz realmente desenvolveria a habilidade oral de modo eficiente, alcançando a almejada fluência.

Essas considerações sobre o discurso de aprendizes já foram apontadas, também, por Grigoletto (2000). Assim, de um modo geral, acredita-se que a escola particular realmente ensina a falar enquanto a escola pública se restringe ao ensino de gramática. Já os cursos on-line ganharam existência tão-somente após o advento da Internet. No Brasil, isso se deu por volta da década de 1990. O recrudescimento dessa modalidade de ensino é, sem dúvidas, incontestável nos últimos vinte anos.

Restringimos nossas observações às relações entre o ensino de idiomas de cursos particulares e públicos. Certamente a globalização, a abertura do mercado internacional, e a expansão tecnológica, só para citar três exemplos, fomentaram a criação de novos cursos de inglês. 
Feitas essas considerações, antes de avançarmos para o tópico seguinte em que trataremos sobre os institutos de idiomas a fim de realizar uma sua caracterização, apontamos algumas conclusões a que chegamos neste tópico: a) desde sua instituição no Brasil, o acesso à educação formal de língua inglesa foi exclusividade de poucos; b) apesar de se haver instituído o ensino de língua inglesa no Brasil há cerca de dois séculos e, desde então, existir um número considerável de leis e decretos garantindo seu ensino nas escolas públicas, o ensino das habilidades de produção e recepção oral compete, em grande medida, aos institutos particulares de idiomas. Em outros termos, falar inglês é ainda privilégio de uma minoria. c) A dependência linguística, já apontada por outros estudiosos (ver, por exemplo, PAIVA, 1996) é reflexo da dependência estrangeira, em especial da econômica. Ainda sim, grande parte dos aprendizes brasileiros de língua inglesa tendem a buscar uma identificação com o norte-americano ocorrendo uma espécie de "endeusamento ianque" abrasileirando, ao nosso gosto, hábitos, práticas e vocabulário anglófonos.

\section{Especificidades do sujeito enunciador: breve caracterização do instituto}

Quem é o sujeito que endossa a peça publicitária tomada para análise neste artigo? A partir desta questão necessária, avançaremos, neste tópico, com o intuito de efetuar uma descrição do instituto, delimitando os aspectos principais que vêm ao encontro dos interesses do trabalho e em articulação com as condições de produção do discurso.

Nesse sentido, destacamos a modalidade de ensino com que trabalha, seu alcance social, quer seja a quantidade média de unidades e, também, a metodologia utilizada pelo instituto. Reiteramos que nossa proposta, em momento algum, é verificar a qualidade da metodologia do instituto, nem tampouco se seu método é mais ou menos eficiente do que outros. Uma observação do método utilizado pode servir para demonstrar como o instituto, na heterogeneidade de seus discursos, produz sujeitos (particularmente o aprendiz brasileiro de língua inglesa), e constrói verdades atinentes ao nativo e à aprendizagem da LE. Servirá também para demonstrar, mesmo nas diferenças, quais são as regularidades que perpassam a formação discursiva sobre "aprendizagem de língua inglesa".

O Instituto ora analisado trabalha exclusivamente com o ensino de língua inglesa na modalidade presencial, foi fundado no Rio de Janeiro em 20 de julho de 1934 e, de acordo com informações coletadas do sítio eletrônico de um franqueado, foi a primeira rede de ensino de língua inglesa no Brasil.

Desse modo, atua há cerca de oito décadas no país. Em 1940 a escola se tornou centro oficial para aplicação dos exames internacionais de língua inglesa como língua estrangeira da Universidade de Cambridge. Verificamos, nos diferentes sítios eletrônicos visitados, e isso em virtude de não existir uma escola "sede", ou seja não há uma 
página eletrônica principal comum a todas as unidades do Instituto ${ }^{2}$, que em todos eles há considerável espaço no que tange aos "Exames de Cambridge". É relevante salientar, sobre a certificação internacional, que os exames CAE (Certificate in Advanced English) e CPE (Certificate of Proficiency in English) são ambos reconhecidos pelo Ministério da Educação e Cultura no Brasil, permitindo ao seu possuidor a eliminação de disciplinas em instituições oficiais de ensino superior que oferecem a língua inglesa em seu currículo, como é o caso dos cursos de Letras com habilitação em língua inglesa.

Constatamos que esse instituto está presente em 70 cidades brasileiras, incluindo os grandes centros. Entretanto, verificamos que há diversas unidades espalhadas nas principais capitais como, por exemplo, na cidade do Rio de Janeiro onde há 26 unidades da escola. Na capital de Minas Gerais, Belo Horizonte, há 15 unidades. Já na cidade de Uberlândia, há três. Assim, existem cerca de 150 unidades do instituto espalhadas pelo país.

Sobre o método de ensino, em relação ao inglês geral, a instituição pauta-se em uma perspectiva comunicativa com foco nas quatro habilidades básicas: leitura, escrita, escuta e fala, com ênfase na produção oral. Não há um material próprio, ao contrário, cada instituto se utiliza de materiais importados adquiridos por editoras tais como Oxford University Press, Longman ou Cambridge University Press. Ainda sobre o método, enuncia-se em seu sítio eletrônico:

O método utilizado no Instituto segue uma abordagem comunicativa, em que o inglês é apresentado e praticado da mesma maneira que é utilizado na vida real. Os cursos são completos, porque desenvolvem todas as habilidades necessárias à comunicação em inglês (escrita, leitura, expressão e compreensão oral). As turmas são segmentadas por faixa etária e nível de conhecimento do idioma. O material didático é de altíssimo padrão internacional. Assim sendo, com professores altamente qualificados, e com aulas dinâmicas enfatizando a conversação, o sucesso do Instituto vem se repetindo a cada década, e comprovado pelo alto nível de aprovação nas provas internacionais da Universidade de Cambridge.

Após essas considerações, avançaremos para o tópico seguinte tratando sobre as especificidades teórico-metodológicas adotadas em nossas análises.

\section{Análise do discurso e enunciado}

Pautamo-nos nos pressupostos teórico-metodológicos advindos da arquegenealogia de Michel Foucault (1995 [1969]), em especial tomando os conceitos de prática

\footnotetext{
A despeito de não existir uma sede, há uma Associação nacional que além de, por exemplo, organizar eventos anualmente, apresenta informações gerais sobre as diferentes unidades do instituto.
} 
discursiva, enunciado, sujeito, saber, verdade e poder, bem como na noção de subjetividade. Esta última noção (de subjetividade) nos é importante uma vez que o discurso publicitário é tomado, neste artigo, como um dispositivo que atua de maneira contundente na produção de sujeitos.

Sob os pressupostos da $\mathrm{AD}$, teoria e metodologia não se separam, portanto, para melhor compreender o processo de produção de sentidos dos discursos, esses conceitos serão tomados como aparatos de interpretação nos procedimentos analíticos.

Para procedermos às análises dos enunciados extraídos do corpus, selecionamos os enunciados (verbais e não verbais) nele presentes, além de outros possíveis dispositivos que emergirem e integrarem essas materialidades (tais como os objetos e as legendas). Procuramos observar os efeitos de sentido depreendidos desses enunciados, bem como as posições ocupadas e verdades construídas e sustentadas pelo sujeito enunciador em relação ao aprendiz brasileiro de língua inglesa. Além disso, no batimento descriçãointerpretação, buscamos compreender o funcionamento desses discursos dando ênfase à questão de como determinadas substâncias em que se investem as materialidades corroboram a produção de sentidos.

Ademais, a metodologia de análise não consiste em uma leitura horizontal, ou seja, em extensão, do início ao fim de cada propaganda tentando encontrar uma completude de sentido, em virtude do primado de incompletude inerente à linguagem (HENRY, 1993). Realizaremos uma análise em profundidade, buscando uma exaustividade vertical como dispositivo analítico (ORLANDI; GUIMARÃES; TARALLO, 1989), lançando mão da construção de verdades, dos efeitos de memória, das relações saberpoder estabelecidas, dando ênfase à atuação das substâncias do som e da expressão, de forma a demonstrar o funcionamento discursivo e os efeitos de sentido produzidos pelas matérias significantes.

Para se efetuar as análises, lançamos mão da noção de enunciado segundo os postulados de Foucault (1995 [1969]). Em face da heterogeneidade própria dos discursos, a peça publicitária é composta por um conjunto de enunciados que se entrecruzam e se dispersam; cada enunciado funciona como um fragmento da situação discursiva e a análise empreendida efetua-se por meio da seleção dessas unidades extraídas do corpus.

Embora como procedimento metodológico nossa proposta seja extrair os enunciados e os analisar separadamente, em cada gesto analítico, levamos em consideração os sentidos produzidos pela propaganda considerando seus diferentes objetos e atentandose para a ligação existente entre eles, mesmo que haja elementos que não estejam explicitados no enunciado específico sob análise.

O enunciado é tomado assim como Foucault (1995 [1969], p. 90) o concebe, isto é, como um "elemento suscetível de ser isolado e capaz de entrar em jogo de relações com outros elementos semelhantes a ele". Para este autor, o enunciado é um pequeno fragmento que precisa de um suporte material, tem uma data e lugar, e é produzido por um sujeito, não se reduzindo e nem tampouco se confundindo com palavra ou frase.

A análise do enunciado leva-nos a refletir sobre as regras que estabelecem suas condições de irrupção, sua produção na história, suas correlações com outros enunciados, 
seu papel desempenhado em meio a outros no jogo enunciativo, seus limites, qual memória é retomada e efeitos de sentidos que emanam dessas práticas. Sob essa base teórico-metodológica, a análise se dá não na busca de um sentido veraz, mas do "real do sentido em sua materialidade linguística e histórica", conforme bem nota Orlandi (2009 [1999], p. 59). Buscamos, nesse processo de interpretação, apreender as margens discursivas, considerando a opacidade, a não-fixidez dos sentidos, as inconsistências e as contradições próprias do discurso no cerne das regularidades apresentadas.

Feitas essas considerações, avançaremos para o tópico seguinte, com vias a procedermos à análise do corpus.

\section{Aprendiz e aprendizagem de língua inglesa no Brasil em análise}

Neste tópico, procederemos às análises da peça publicitária, pautados no construto teórico da AD francesa (PÊCHEUX, 1988 [1975], 1999 [1983], 2002 [1983]) e em constante diálogo com as profícuas problematizações histórico-críticas sobre o sujeito e o discurso em Michel Foucault (1984 [1982], 1988, 1989 [1973], 1995 [1969]).

A seleção de enunciados se efetua mediante as regularidades discursivas que embasam a análise que se propõe realizar, sendo que serão apresentadas análises de duas peças veiculadas em canais abertos de televisão e também disponíveis nos sítios eletrônicos dos cursos de inglês.

A peça publicitária do Instituto, difundida em seu canal on-line, é uma entrevista informal realizada no centro de uma cidade brasileira, à noite, por uma jovem mulher (talvez professora) vinculada ao curso de línguas (A) a dois estudantes brasileiros (B, C), também jovens. É uma propaganda um pouco mais extensa do que o comercial televisivo, contendo em média um minuto e trinta segundos.

A propaganda tem o seguinte formato: essa possível professora, do referido instituto, sai à rua em busca de entrevistar pessoas em inglês. Nessa feita, expõe as tentativas mal sucedidas de seus interlocutores ao se expressarem na referida língua. O propósito do instituto é, também, destacar que seu aprendiz, ao contrário dos entrevistados, não precisa utilizar-se de "embromation" (título da série de propagandas) para se comunicar.

Diferente de todas as propagandas anteriormente analisadas, esta peça publicitária é interessante no sentido de apresentar uma entrevista "real", feita na rua com indivíduos "reais" e não com personagens ou mesmo preparada em estúdio ${ }^{3}$. Na verdade, o que ocorre é uma espécie de simulacro de espontaneidade, pois, se por um lado a propaganda não é totalmente produzida de antemão ${ }^{4}$, por outro lado, não se pode olvidar que há edição após a realização da entrevista e que o enunciador certamente seleciona os fragmentos que melhor atendem a suas propostas políticas, ideológicas e pedagógicas

\footnotetext{
Isso não significa afirmar que não houve seleção e edição das mensagens veiculadas.

${ }_{4}$ Totalmente porque os entrevistados parecem agir espontaneamente. A entrevistadora, por sua vez, certamente se prepara de algum modo.
} 
e a seus interesses publicitário-comerciais. Outrossim, o que se almeja é evidenciar os erros e desvios cometidos pelos aprendizes brasileiros.

Em relação à sua composição (da peça publicitária), são utilizados alguns recursos de imagem e som em sua edição, tais como legendas e sons artificiais. Neste ínterim, a propaganda inicia-se com a referida entrevistadora que, ao se aproximar dos dois estudantes/aprendizes brasileiros ${ }^{5}$, pergunta-lhes:

\section{A - Excuse me. Can I talk to you for a moment? \\ Can you help me? Do you speak English? ${ }^{6}$}

De modo geral, se analisarmos o diálogo entre a entrevistadora e os entrevistados (estudantes/aprendizes brasileiros), perceberemos que um destes últimos, a despeito dos erros e desvios linguísticos cometidos, consegue se comunicar. Sua pronúncia, a propósito, é adequada para um estudante que declara falar "mais ou menos". Por adequado queremos dizer que a formação sintática das frases é ordenada, a escolha lexical é pertinente, as respostas são coerentemente respondidas, o aluno compreende bem o que se lhe pergunta, e não hesita em nenhuma das questões. Entretanto, mesmo que a fala do jovem estudante seja inteligível apenas sua pronúncia apresenta alguns desvios, ocasionados pela interferência da L1. Por exemplo, após a primeira pergunta o diálogo segue:

A - Where are you guys gonna go dance tonight?

B - My house. We can go to my house.

C - I wanna go dance tonight.

A - Are you inviting me to go to your house?

B - Yeah, "May bee", maybe.

A - Oh, my God!

All you guys are going to your house?

B - No. Just you and me.

A - Ah, I understand that. Well, ok.

But, you speak English?

Very well?

B - Not very well, but I can "uon"...7

\footnotetext{
A despeito de serem estudantes, a propaganda não explicita se os entrevistados são aprendizes de LE de alguma instituição de ensino. O fato é que um deles já tem alguma experiência de aprendizagem da língua em virtude de conseguir se comunicar com a entrevistadora.

6 Com licença, posso falar com você um instante?

Pode me ajudar? Você fala inglês? (Tradução da legenda).

7 Quando não houver tradução nas legendas da propaganda, a tradução é nossa (negrito):

A - Onde é que vocês vão dançar hoje à noite?

B - Minha casa. Nós podemos ir para minha casa.

$\mathrm{C}$ - Eu quero ir dançar hoje à noite.

A - Você está me convidando para ir para sua casa?

B - Sim, "May bee", talvez.
} 
Observa-se, então, que as perguntas realizadas pela entrevistadora ao estudante/ aprendiz são adequadamente respondidas. Quando ela indaga onde eles vão dançar, ele brinca em inglês: Na minha casa. Nós podemos ir para minha casa. Nesse sentido, ele está flertando a garota na língua-alvo. Na sequência, um pouco desconcertada, aquela que realiza as perguntas tenta confirmar se entendeu: Você está me convidando para ir para sua casa?. E ele prontamente responde, nesse momento, atenuando a força do convite: Sim, talvez. Em seguida, ela ainda confirma se todos os colegas também vão para a casa dele. E ele declara: "Não, apenas você e eu". Como é notório, o diálogo flui com naturalidade até o momento em que a entrevistadora indaga: "Mas, você fala inglês? Muito bem?" - observa-se que a conjunção adversativa não é traduzida, na legenda, apesar de ser enunciada em inglês. Essa indagação aponta a posição que o sujeito ocupa no discurso, ou seja, de manter um diálogo qualquer, cabendo-lhe realçar que seu interlocutor não fala inglês tão bem quanto ela. Busca-se, pois, construir um discurso de deslegitimação. Aliás, no início da alocução tal assertiva já havia sido feita. No entanto, parece que o fato de o diálogo ter caminhado com dada naturalidade interferiu nos objetivos do enunciador.

Sobre as substâncias da expressão em articulação com o sonoro, por exemplo, após a pergunta se ele fala inglês muito bem (ele, no singular, pois o diálogo é direcionado a apenas um estudante), o aprendiz responde: Não muito bem, mas eu posso... Imediatamente, a entrevistadora indaga: Pode o quê? E ele enuncia: Eu posso falar com você. De imediato ela retruca: Falar o quê?. Na verdade, sua pergunta, "What?" - em inglês, rapidamente realizada com ligeiro aumento na intensidade vocal, agregado ao tom da indagação, e seguida de uma ligeira pausa indicia certa incredulidade por parte não da entrevistadora em si, mas do sujeito que ocupa a posição no discurso. Assim, mais do que o dizer em si, observa-se a produção discursiva como efeito desses lugares. Na verdade, o que rege o discurso, mais do que o conteúdo linguístico ou semiológico, são as determinações históricas dos sujeitos. Em outros termos, o linguístico e o semiológico são um efeito das posições que esses mesmos sujeitos ocupam no interior da prática discursiva.

Sobre a mobilização de substâncias no âmbito visual, é relevante o uso de legendas na propaganda - uma vez que o diálogo se dá em inglês. Todavia, se as frases formadas pela entrevistadora surgem sempre na cor branca, quando o entrevistado enuncia uma expressão com algum tipo de desvio (são poucos, os quais não interferem na comunicação) as mesmas aparecem sempre em vermelho.

Assim, as substâncias funcionam na materialidade para dar realce ao erro. Se não bastasse o realce cromático, há também a utilização de aspas nas frases como forma

\footnotetext{
A - Oh, meu Deus!

Todos vocês vão para sua casa?

B - Não. Só você e eu.

$\mathrm{A}-\mathrm{Ah}$, saquei. Está certo.

Você fala inglês?

Muito bem?

B - Não muito bem, mas eu posso...
} 
de destacar esses desvios. Por exemplo, quando o estudante/aprendiz responde Yeah "May bee”, maybe., constata-se que apesar da enunciação ser feita com vogal longa [i:] na primeira tentativa de enunciação da partícula adverbial, ao invés da vogal curta [i], imediatamente o estudante realiza a autocorreção e enuncia sem nenhum desvio. Em outras palavras, o destaque a um desvio, já corrigido pelo próprio falante, aponta para uma exigência, por parte do sujeito, de uma produção linguística que beira a perfeição.

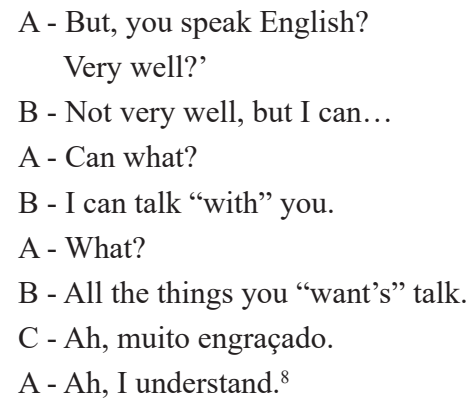

Ainda em resposta à indagação da entrevistadora, o aprendiz/estudante afirma com pronúncia inteligível: I can talk "wifi” you. A problemática do som [ $\theta$ ] é bastante discutida por professores brasileiros de língua inglesa em virtude de se tratar de um fonema desconhecido pelos lusofalantes. É, pois, um fonema que gera dificuldades para ser produzido, pois o som do $[\theta]$, nesse caso, confunde-se com o [f], pois são parecidos (ambas são fricativas surdas). Todavia, a frase, em geral, é completamente inteligível, tanto é que o diálogo segue normalmente. $\mathrm{O}$ estudante/aprendiz brasileiro realmente consegue manter uma conversa com a personagem que assume a posição do instituto de idiomas. No entanto, o sujeito que enuncia busca explicitar, a todo momento, não diríamos a baixa qualidade do inglês de seu interlocutor (uma vez que nesse diálogo o estudante brasileiro consegue manter a conversa), mas sim os poucos desvios cometidos por ele.

A busca ou "caça" aos erros perpassa o discurso do sujeito enunciador e evidencia seu exercício de poder. No âmbito sonoro, por exemplo, bem ao início da peça publicitária, há uma música que bem lembra um filme de detetive. Como abertura, a música prepara o enunciatário para aquilo que atravessa o comercial.

\footnotetext{
A - Você fala inglês?

Muito bem?

B - Não muito bem, mas eu posso...

A - Pode o quê?

$\mathrm{B}-$ Eu posso falar com você.

A - Falar o quê?

$\mathrm{B}$ - Todas as coisas que você quiser falar.

$\mathrm{C}-\mathrm{Ah}$, muito engraçado.

$\mathrm{A}-\mathrm{Ah}$, saquei.

(Em negrito, tradução nossa)
} 
Ora se compete ao detetive investigar, muitas vezes algo não evidente, nesse caso, pela intersonoridade, subjaz dada compreensão de que se efetua certa "investigação" com o intuito de explicitar, reiteramos, os erros linguísticos cometidos pelo outro e, também, demonstrar que aquele que fala, fala de um determinado lugar, e "sabe" o que realmente está falando. Instaura-se, pois, um discurso de deslegitimação do entrevistado, como forma de legitimação de si. Um procedimento mobilizado que integra os exercícios de poder do sujeito ocasionando, por consequência, a produção de sujeitos.

Desse modo, os sentidos produzidos no decurso da propaganda nos levam a concluir que o discurso do instituto ora analisado é excludente, sendo que o sujeito manda um recado à sociedade de que não basta se comunicar, é preciso falar perfeitamente ao invés de, ao menos, tentar se expressar. Diferentemente do que, por exemplo, Pennington (1996) destaca, isto é, que o mais relevante é a comunicação em si (se ela se der de modo inteligível), não importando as "falhas" no processo; nesses discursos, os desvios e erros (reiteramos, não impeditivos de compreensão entre os participantes do diálogo) são tidos como um grande defeito. Portanto, utilizar-se de léxico com desvios de pronúncia ou frases mal formadas é inconcebível para o sujeito enunciador. Assim, uma verdade que se constrói é que a precisão linguística (especialmente fonética e gramatical) é muito mais importante do que a comunicação em si.

\section{Considerações finais}

Tomando a prática discursiva como um conjunto de regras “[...] históricas, sempre determinadas no tempo e no espaço, que definem em uma dada época e para uma determinada área, social, econômica, geográfica ou linguística, as condições de exercício da função enunciativa" (FOUCAULT, 1995 [1969], p. 136), percebemos algumas regularidades que definem as condições de exercício da função enunciativa na formação discursiva atinente ao aprendiz brasileiro e à aprendizagem de língua inglesa.

Assim, na parte relativa à substância sonora, a pronúncia é um aspecto da aprendizagem da língua que o sujeito enunciador coloca em evidência. No que tange às verdades construídas nas relações do brasileiro com a língua inglesa, fica evidente a exigência por parte do sujeito enunciador sobre o aprendiz brasileiro ter que possuir pronúncia perfeita, equivalente ao falante nativo. Seu desvio (na pronúncia) é sinônimo de um inglês fraco e ruim, ocasionando, como consequência, a deslegitimação completa desse sujeito.

Logo, o desvio/erro recebe destaque, e seu autor é, consequentemente, ironizado. Ademais, o sujeito demonstra, em seus discursos, que a comunicação não é tão importante, como o é a precisão fonética. Em outros termos, o sujeito que demanda apenas o conhecimento sistêmico, descontextualizado, atende ora à perspectiva que enxerga a língua como reflexo do pensamento, ora como veículo para transmitir informações, ambas desvinculadas do contexto social. Assim, a análise da peça publicitária deste 
artigo nos permite compreender, em certa medida, qual é a concepção de linguagem que constitui o sujeito enunciador.

A partir das análises verificamos, também, existir um apagamento das outras três habilidades comunicativas básicas, isto é, da recepção escrita, produção escrita e recepção oral em detrimento da produção oral. Assim, os enunciados evidenciam a importância suprema dessa habilidade, além da constante mobilização linguística do lexema falar em suas diversas flexões. Na peça publicitária o aprendiz consegue entender a língua falada na América do Norte muito bem, tanto é que ele responde às questões apropriadamente sem hesitar, demonstrando sua capacidade de compreensão oral. Todavia, não é essa a habilidade que conta. Aliás, a leitura e a escrita, também como habilidades básicas, não são sequer mencionadas no interior dessa formação discursiva. Portanto, o que importa para o sujeito enunciador analisado e que recebe destaque em seu discurso não é o fato de o aprendiz brasileiro saber inglês, mas notadamente falar inglês. Aliás, falar muito bem.

MARQUES, W. Historical Aspects of English language teaching in Brazil: a discursive analysis of the subject in audiovisual publicity of language couses. Alfa, São Paulo, v.65, 2021.

- ABSTRACT: Under the theoretical framework of discourse analysis, this paper presents as general objective analyze the constitution of the subject in the advertising discourse of language courses in Brazil. In this sense, we will analyze how the subject means learner and English language learning in these enunciative spaces. For this, we will bring to discussion, a priori, some historical aspects that permeate the teaching of English language in our country. Following, we will address the methodological basis which constitutes the research, and, in the end, we will propose our analysis. We highlight, in the analysis, that the enunciates, on an ongoing basis, demonstrate the paramount importance of the oral skill. This is presented in the constant linguistic mobilization of the lexeme speak in its various inflections. Furthermore, it is verified the supremacy of the native in relation to the Brazilian and, finally, the requirement that lies on the Brazilian learner of the English language concerning the need for "perfect" pronunciation.

- KEYWORDS: Learner. Learning. Discourse. English language. Advertising.

\section{REFERÊNCIAS}

BAUMAN, Z. Identidade. Entrevista a Benedetto Vecchi. Trad. de Carlos Alberto Medeiros. Rio de Janeiro: Jorge Zahar, 2005.

COURTINE, J-J. Metamorfoses do discurso político: derivas da fala pública. Trad. de Nilton Milanez e Carlos Piovezani Filho. São Carlos, SP: Claraluz, 2006. 
FOUCAULT, M. A hermenêutica do sujeito: curso dado no Collège de France (19811982). Trad. de Márcio Alves da Fonseca e Salma Annus Muchail. 3. ed. São Paulo: Martins Fontes, 2010.

FOUCAUlT, M. A ordem do discurso. 2. ed. São Paulo: Edições Loyola, 1996. Original de 1971.

FOUCAULT, M. A arqueologia do saber. 6. ed. Rio de Janeiro: Forense Universitária, 1995. Original de 1969.

FOUCAULT, M. Isto não é um cachimbo. 3. ed. São Paulo: Paz e Terra, 1989. Original de 1973.

FOUCAULT, M. História da sexualidade 1: a vontade de saber. Trad. de Maria Thereza da Costa Albuquerque e J. A. Guilhon Albuquerque. Rio de Janeiro: Edições Graal, 1988. FOUCAULT, M. O sujeito e o poder. In: RABINOV, P.; DREYFUS, H. Michel Foucault: uma trajetória filosófica, para além do estruturalismo e da hermenêutica. Trad. de Vera Porto Carrero. Rio de Janeiro: Forense Universitária, 1984. p. 229-249. Original de 1982.

GRIGOLETTO, M. Representação, identidade e aprendizagem de língua estrangeira. Claritas, São Paulo, v. 6, p. 37-47, 2000.

HENRY, P. Sujeito, sentido e origem. In: ORLANDI, E. P. O discurso fundador. Campinas: Pontes, 1993. p. 151-162.

IANNI, O. Imperialismo e cultura. Petrópolis: Vozes, 1976. (Coleção Sociologia Brasileira, 5)

MOACYR, P. A instrução e o império. São Paulo: Companhia Editora Nacional, 1936. 3. V.

MOITA LOPES, L. P. da. Oficina de linguística aplicada: a natureza social e educacional dos processos de ensino/aprendizagem de línguas. Campinas, SP: Mercado de Letras, 1996.

OLIVEIRA, L. E. M. de. A historiografia brasileira da literatura inglesa: uma história do ensino de inglês no Brasil (1809-1951). 189 f. 1999. Dissertação (Mestrado em Teoria Literária) - Instituto de Estudos da Linguagem, Universidade Estadual de Campinas, Campinas, SP, 1999.

ORLANDI, E. Análise de discurso: princípios e procedimentos. 8. ed. Campinas: Pontes, 2009. Original de 1999.

ORLANDI, E.; GUIMARÃES, E.; TARALLO, F. Vozes e contrastes: discurso na cidade e no campo. São Paulo: Cortez, 1989. 
PAIVA, V. L. M. de O. e. A língua inglesa no Brasil e no mundo. In: PAIVA, V. L. M. de O. e (org.). Ensino de Língua Inglesa: reflexões e experiências. Campinas, SP: Pontes, 1996. p. 9-29.

PÊCHEUX, M. O Discurso: estrutura ou acontecimento. Trad. de Eni Puccinelli Orlandi. 3. ed. Campinas: Pontes, 2002. Original de 1983.

PÊCHEUX, M. O papel da memória. In: ACHARD, P. et al. O papel da memória. Campinas: Pontes, 1999. p. 49-57. Original de 1983.

PÊCHEUX, M. Semântica e discurso: uma crítica à afirmação do óbvio. Trad. de Eni Puccinelli Orlandi et al. Campinas: EdUnicamp, 1988. Original de 1975.

PENNINGTON, M. Phonology in English Language Teaching. London: Longman, 1996.

PINTO, V. Comunicação e Cultura Brasileira. São Paulo: Ática, 1986. (Coleção Princípios, v. 56).

WOODS, D. Teacher cognition in language teaching: beliefs, decision making and classroom practice. Cambridge: Cambridge University Press, 1996.

Recebido em 21 de dezembro de 2015

Aprovado em 27 de fevereiro de 2016 